\title{
Knowledge translation and the science of pain
}

\author{
Kenneth D Craig PhD
}

$\mathrm{C}$ urrent preoccupation with the magnitude, severity, misery and economic challenges of chronic pain has led to diverse demands. On one hand, the recognition that persisting high levels of suffering reflect inadequacies in our understanding of acute and chronic pain leads to calls for improved support of scientific investigation capable of penetrating the mysteries and advancing knowledge. At the same time, it is appreciated that striking advances in understanding pain over the past several decades have not been adequately translated into substantial reductions in the suffering and costs that are attached to pain. In consequence, demands for improved

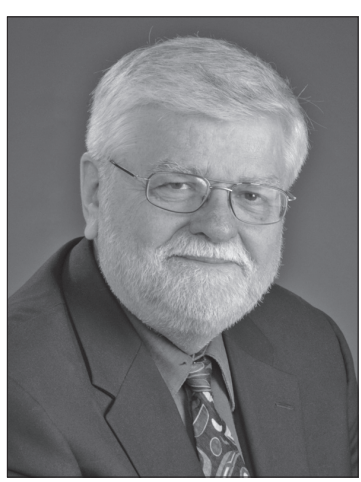

Kenneth D Craig from the Parliament of Canada both the advancement and translation of knowledge into improved health for Canadians. All applicants to the Canadian Institutes of Health Research (and other national research councils) must justify their research in terms of application and provide plans demonstrating how they will disseminate research beyond academic and scientific circles. These requirements are often perceived as frustrating and irrelevant to the challenges of good science.

Please consider this an invitation to scientists, whether interested in basic biological or behavioural science, clinical science, social and cultural determinants of health, or health service delivery, to use Pain Research $\mathcal{E}$ Management knowledge translation are accelerating. Is it possible that both the requirements of science and the community at large would benefit from greater attention to ensuring that advances in knowledge are indeed translated into applications that benefit people?

That appears to be one of the many questions that arise from Henry's provocative paper "The need for knowledge translation in chronic pain", which is published in the present issue of Pain Research $\mathcal{E}$ Management. In the preceding editorial "Do we care about people with chronic pain?", Lynch very effectively addressed the paper as a manifesto justifying and calling for a change in how pain is conceptualized if we are to transform the health service delivery system to better serve Canadians and those legions of others caught up in the epidemic of chronic pain.

I am intrigued by the somewhat different but complementary question, 'Are there prospects for Pain Research $\mathcal{E}$ Management serving as a vehicle that would permit scientists to demonstrate the implications and importance of their research for improving the lives of people who suffer excessive or unnecessary acute or chronic pain?'. As Henry observed, the Canadian Institutes of Health Research has as its mandate as a publication outlet for papers explaining and exploring translation of their research into improved health for Canadians. It is intriguing that a basic scientist, James Henry, distinguished by outstanding research in molecular mechanisms of pain, and Scientific Director of the Michael G DeGroote Institute for Pain Research and Care (McMaster University, Hamilton, Ontario), would seize the initiative to carefully and provocatively examine issues concerning population health and health service delivery. While scientists typically favour specialty journals for focused empirical papers, there is a great need for integrative, even speculative, reviews and theoretical analyses. There are many outstanding Canadian scientists who could accept this challenge. The title of our journal signals an interest in this type of integration. Readers of the Journal are broadly representative of research and pain management and would find the papers of great interest. It would be a pleasure to provide editorial review of papers of this type.

Kenneth D Craig PhD Editor-in-Chief Pain Research $\mathbb{E}$ Management 


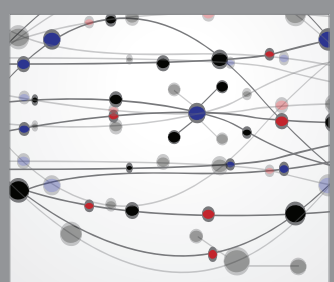

The Scientific World Journal
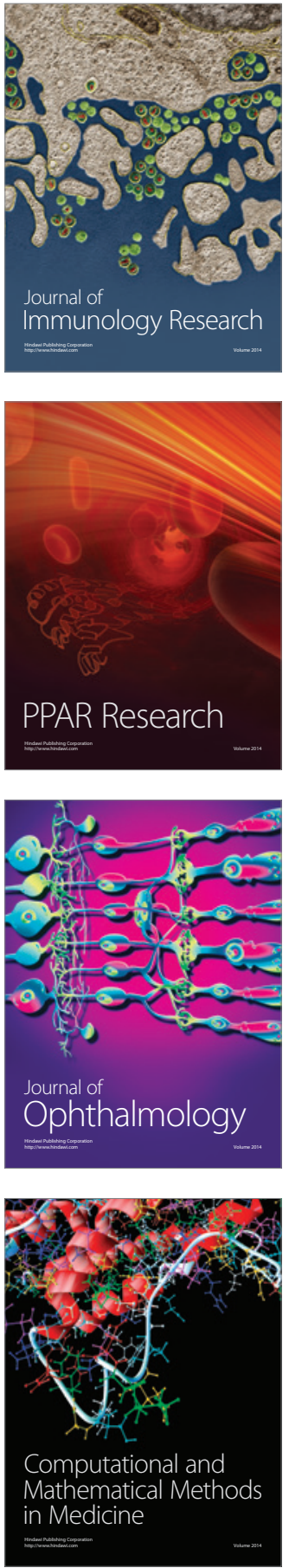

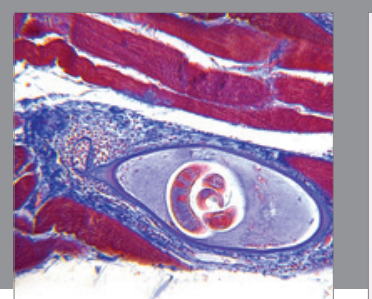

Gastroenterology Research and Practice

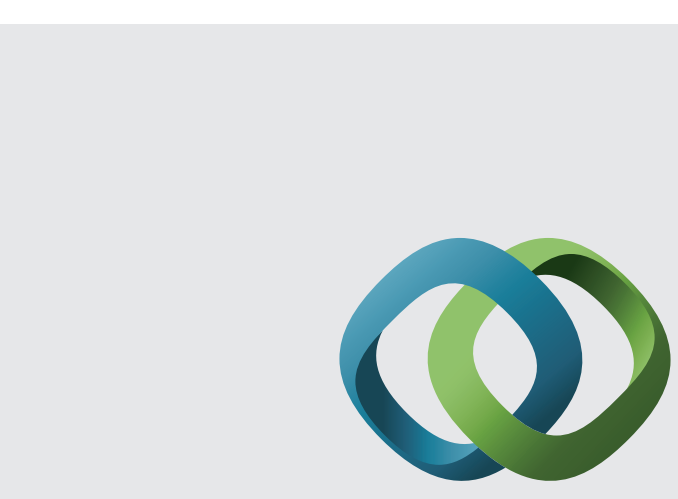

\section{Hindawi}

Submit your manuscripts at

http://www.hindawi.com
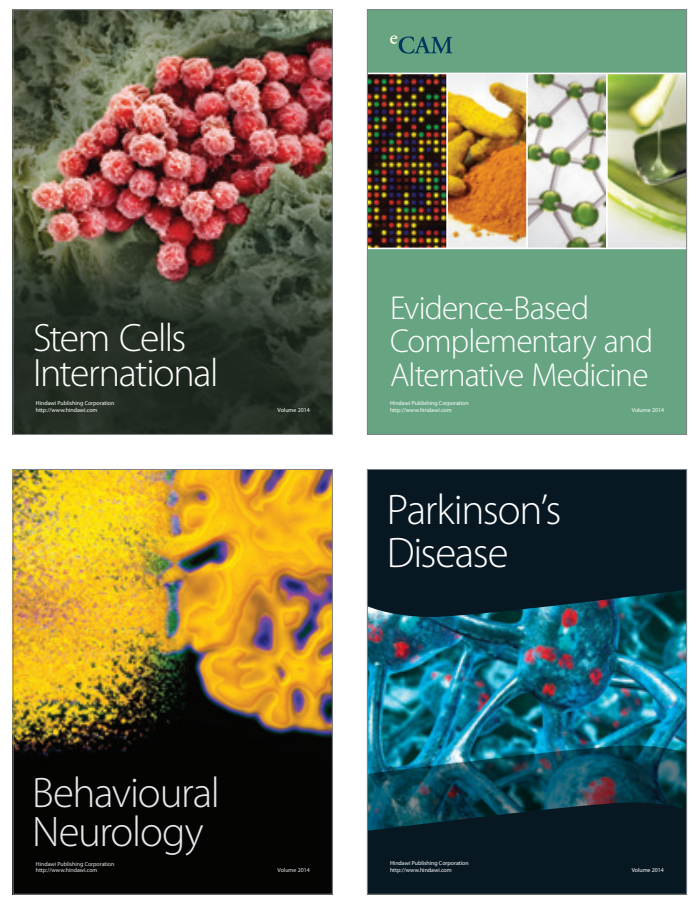
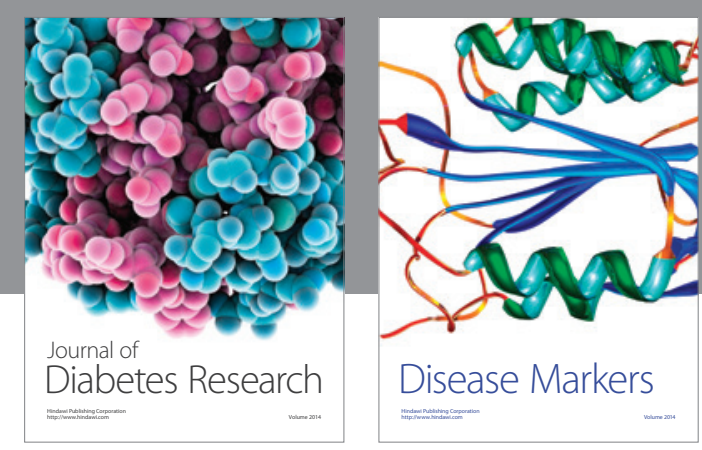

Disease Markers
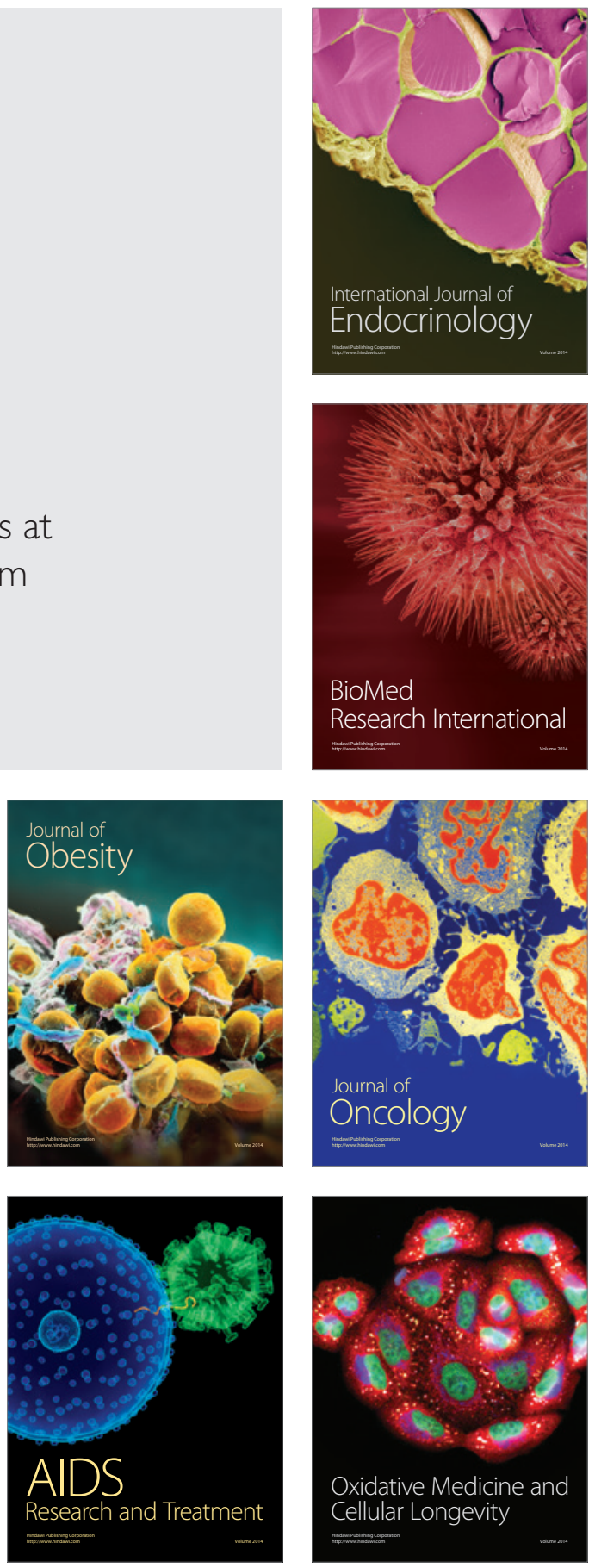